\title{
Batch Processing in Preassembled Die Sets-A New Process Design for Isothermal Forging of Titanium Aluminides
}

\author{
Markus Bambach †, Irina Sizova, Alexander Sviridov, Johan Andreas Stendal * \\ and Martin Günther
}

Chair of Mechanical Design and Manufacturing, Brandenburg University of Technology Cottbus-Senftenberg, Konrad-Wachsmann-Allee 17, Cottbus D-03046, Germany; Markus.Bambach@b-tu.de (M.B.); sizova@b-tu.de (I.S.); sviridov@b-tu.de (A.S.); Martin.Guenther@b-tu.de (M.G.)

* Correspondence: Stendal@b-tu.de; Tel.: +47-94-111-994

† Current address: Panta Rhei Gebäude, Konrad-Wachsmann-Allee 17, 03046 Cottbus, Germany.

Received: 30 November 2017; Accepted: 19 December 2017; Published: 1 January 2018

\begin{abstract}
Titanium aluminide (TiAl) turbine blades produced by isothermal forging have recently been implemented in the low-pressure part of commercial aircraft jet engines. However, the slow speed of isothermal forging, costly molybdenum-based dies and the required protective forging atmosphere makes the process rather expensive. Currently, industrial forging is done by closed-die isothermal forging processes with stationary dies. Idle time occurs when single parts are inserted and extracted from the dies. As an interesting alternative for forging small parts, a new set-up is devised and explored in this work, i.e., batch processing. Using a die set which allow for off-line preassembly and preheating, multiple parts can be forged in one stroke. The design of the batch process was based on a new material model, which was implemented into a finite element system to identify the forging parameters. The setup of the press transport system for batch processing, as well as the results of the simulations and forging experiments are presented. A cost comparison between the new process and conventional forging with stationary dies concludes that for smaller parts such as compressor blades, batch processing offers advantages regarding productivity and cost.
\end{abstract}

Keywords: batch processing; titanium aluminide; isothermal forging; material modelling

\section{Introduction}

Intermetallic titanium aluminides (TiAl) are promising lightweight materials for high-performance components such as turbine blades in aircraft jet engines. These alloys are attractive due to the combination of low density, high strength and oxidation/corrosion resistance [1,2]. Recent work by Aguilar et al. [3] describes the set-up of an investment casting facility for low-pressure turbine blades. In the jet engine of the Airbus A320Neo aircraft, the first series application of forged TiAl blades has recently been accomplished [4]. To make forging of TiAl viable, alloys that solidify through the $\beta$-phase were developed. The $\beta$-phase acts like a lubricant between the hard phases $(\gamma$-TiAl and $\alpha 2$-phase) during forging. Due to the high material cost and cost-intensive finishing operations of difficult-to-machine TiAl alloys [5,6], near-net shape forgings are desirable. However, the latest generation of alloys still exhibit poor workability and must therefore be shaped by isothermal forging processes [7].

Isothermal forging at temperatures of roughly $1250{ }^{\circ} \mathrm{C}$ with strain rates of $\sim 10^{-2} \mathrm{~s}^{-1}$ is time-consuming and demands for expensive molybdenum-based die materials, which are subject to heavy oxidation at temperatures above $625^{\circ} \mathrm{C}$ and require a protective atmosphere or even vacuum. In order to compensate for the high process and tooling costs, the forging process has to be optimized 
for productivity while maintaining the necessary quality. Forging of TiAl is typically carried out as a closed-die isothermal forging process with stationary dies, into which billets are inserted before forging and extracted after forging. Manipulation of parts causes idle time for the forging press. The idle time increases tremendously if a forged part sticks to the tool surface, which happens regularly due to long forging strokes ( $\sim 4-5 \mathrm{~min}$ ) and relatively large glide distances between workpiece and tool.

The literature consists mostly of basic research on the isothermal forging of TiAl alloys. In addition, studies on the modeling of flow stress and dynamic recrystallization of austenitic steels were transferred to titanium aluminides. However, in-depth studies on the modelling and design of industrially viable forging processes of TiAl alloys are missing from the literature. Depending on part geometry and lot size, more cost-efficient production can be achieved by using innovative process designs. Small parts (e.g., compressor blades) require moderate forming forces and can therefore be grouped together and forged in a single die set as a batch. By preassembling and preheating the die set and billets outside the press, idle time due to handling of single parts can be avoided.

Designing such a batch process requires knowledge of the process window. Depletion temperatures of $\mathrm{TiAl}$ and the strength of the dies limit the lower temperature, while the two-phase region $\alpha+\beta$ and the thermal loads on the dies bound the process window towards higher temperatures. This results in a narrow temperature window, requiring precise temperature control and a priori process design in order to avoid damage to the dies. In addition, the transition from the incipient yield over the peak stress to the steady state is often not well represented in available material models.

This paper aims at introducing and investigating the feasibility of a batch process design for the TiAl alloy TNB-V4. The batch process developed in this work consists of a transport system and a transportable die set, which is preassembled and preheated, fed into a hydraulic press to forge compressor blades, and finally extracted from the press. A previously developed material model, able to accurately predict the flow curve of TNB-V4, was implemented into the FE program Q-Form and validated using hot compression tests. Simulations based on the model and physical experiments were then performed to determine the forging parameters, and assess the feasibility of the developed transport and die design for batch processing. In addition, a cost analysis compares the economic viability of batch processing to stationary die forging. Due to cost restrictions, the authors were only able to produce dies able to forge 1 part per stroke. However, this investigation covers the ground work of material modelling, design of a transport system and a preassembled die set, and cost analysis for batch processing. Furthermore, scaling up of the process to forge 2 and 4 parts per batch is discussed.

\section{Literature Review}

Several studies on the forging process of TiAl-based alloys are reported in the literature. Millett et al. [8] investigated a $\gamma$-TiAl alloy with the nominal composition Ti-48Al-2Mn-2Nb. The authors found an increase in flow softening behavior with increasing temperature and decreasing strain rate (i.e., the opposite of the expected behavior), through examination of the produced stress-strain curves. In order to analyze the flow stress data the authors used the model developed by Blackwell et al. [9]. The alloy was shown to deform via Dynamic Recrystallization (DRX), resulting in a nearly pure $\gamma$-phase microstructure. This $\gamma$ structure has poor fracture toughness and creep resistance, making post-process heat treatment necessary, which can result in very large grain sizes, constraining the application of this alloy. Semiatin et al. [10] reported on isothermal forging of a near $\gamma$-titanium aluminide (Ti-46.6Al-2.7Nb-0.3Ta-0.2O) and found similar results. The investigation suggested that the flow softening was also a result of adiabatic heating. Tetsui et al. [11] investigated hot forging and subsequent machining of a Ti-42Al-5Mn alloy with the aim of supplying large TiAl components with complex shapes and high dimensional precision, expanding the application variety of TiAl alloys. The authors verified that complex configurations were possible to fabricate using hot forging and machining. The presence of $\beta$-phase fractions was found to greatly improve both the hot forgeability and machinability in comparison to conventional TiAl alloys. However, the $\beta$-phase reduces the high-temperature strength of the alloy. 
Furthermore, Finite Element (FE) analyses of the forging of TiAl alloys have been reported. Brooks et al. [12] used two finite element codes (ABAQUS and FORGE 3) to model the forging of a two-phase TiAl (Ti-47.9Al-2.06Nb-1.93Cr-1.07B) turbine blade, with the aim of defining a forging window for isothermal deformation conditions, and comparing the results with isothermally forged parts. The model produced reasonable predictions for load and strain, and showed good agreement with the observed microstructure. The flow softening of the $\gamma$-phase was found to be a function of the $\gamma$ grain size and the degree of recrystallization. There have been many investigations on the hot deformation behavior (Semiatin et al. [13], Schmoelzer et al. [14]) as well as on the constitutive modeling of TiAl-based alloys, as these models are needed for accurate FE simulations of isothermal forging processes. The flow behavior of TiAl-based alloys has been studied and a number of constitutive relationships and processing maps have been proposed in the literature. Cheng et al. [15] investigated the flow behavior in hot forging of a high $\mathrm{Nb}$ containing TiAl-alloy (Ti-42Al-8Nb-0.2W-0.1Y) and applied the model proposed by Laasraoui and Jonas [16], which was developed for hot working of steel in the austenitic range. The results revealed an easy onset of DRX, while the Dynamic Recovery (DRV) was impeded. In addition, a low DRX rate as compared to conventional alloys was found.

Werner et al. [17] and Godor et al. [18] applied two phenomenological constitutive models for the description of the hot deformation behavior of different TiAl-alloys, the Sellars-McTegart (ST) model and the Hensel-Spittel (HS) model. Werner et al. [17] investigated the flow behavior of a $\beta$-solidifying TNM (TiAl with $\mathrm{Nb}$ and Mo as the main alloying elements) alloy with the nominal composition Ti-43.5Al-4Nb-1Mo-0.1B. Godor et al. [18] investigated two $\gamma$-TiAl alloys with the nominal compositions Ti-41Al-3Mo-0.5Si-0.1B and Ti-45Al-3Mo-0.5Si-0.1B. Both authors found that the ST model gave good predictions for flow stress, however the model is only valid in the experimental strain range from which the constitutive expression has been derived. The HS model was reported to reproduce the experimental flow stress curves well, in addition to being able to extrapolate stress data to strains outside the experimental range. In addition, both authors found that the calculated Zener-Hollomon parameter could be linked to the dynamically recrystallized grain size through a power law equation. Schwaighofer et al. [19] studied a modified TNM alloy, with the nominal composition Ti-43Al-4Nb-1Mo-0.1B, which contains a small amount of $\mathrm{C}$ and $\mathrm{Si}(\mathrm{C}+\mathrm{Si}$ less than 1 at \%). The authors also applied the Sellars-McTegar model and established processing maps with the demonstration of stable and unstable deformation regions.

The presently available literature on the modelling of TiAl-alloys, specifically the descriptions of the flow behavior, are based on empirical models which were derived originally for steels and do not consider the presence of a multiphase microstructure. Therefore, most of the present models are not able to predict the steep rise of flow stress from incipient yield to the peak stress, and the subsequent drop to the steady state. Modeling the entire course of the flow curve is crucial in predicting material flow in FE simulations, as only the points in the workpiece where local stress exceeds the flow stress will deform plastically. Thus, the state of the art leaves open questions regarding the FE modeling of titanium aluminides, and the design and implementation of new forging processes which make full use of the press capacity.

\section{Materials and Methods}

\subsection{FEA Development}

The material model used in this work was developed and published by Cingara and McQueen [20]. The model accurately predicts the course of flow stress from incipient yield to the peak stress and beyond. The model equations are summarized in Table 1. It uses separate DRX kinetics for the $\beta$ and $\gamma$-phase, as indicated in Equations (8) and (9), where different parameters are used to model these two phases. A wide range of hot compression tests were conducted in order to determine the parameters used in this model. 
Table 1. Model equations for TNB-V4 alloy.

\begin{tabular}{ccc}
\hline Zener Hollomon parameter & $\mathrm{Z}=\dot{\varepsilon} \times \exp \left(\frac{\mathrm{Q}_{\mathrm{W}}}{\mathrm{RT}}\right)$ & $(1)$ \\
\hline Strain hardening & $\sigma(\varepsilon)=\sigma_{\mathrm{p}}\left[\frac{\varepsilon}{\varepsilon_{\mathrm{p}}} \exp \left(1-\frac{\varepsilon}{\varepsilon_{\mathrm{p}}}\right)\right]^{\mathrm{C}}$ & $(3)$ \\
\hline Critical strain & $\varepsilon_{\mathrm{cr}}=\alpha \varepsilon_{\mathrm{p}}$ & $(4)$ \\
\hline Peak strain & $\varepsilon_{\mathrm{p}}=\mathrm{a}_{1} \times \mathrm{d}_{0}^{\mathrm{a}_{2}} \times \mathrm{Z}^{\mathrm{a}_{3}}$ & $(5)$ \\
\hline Steady state strain & $\varepsilon_{\mathrm{ss}}=\mathrm{e}_{1} \times \varepsilon_{\mathrm{m}}+\mathrm{e}_{2} \times \mathrm{d}_{0}^{\mathrm{e}_{3}} \times \mathrm{Z}^{\mathrm{e}_{4}}$ & $(6)$ \\
\hline Peak stress & $\sinh \left(\mathrm{f}_{3} \times \sigma_{\mathrm{p}}\right)=\mathrm{f}_{1} \times \mathrm{Z}^{\mathrm{f}_{2}}$ & $(7)$ \\
\hline Steady state stress & $\sinh \left(\mathrm{h}_{3} \times \sigma_{\mathrm{p}}\right)=\mathrm{h}_{1} \times \mathrm{Z}^{\mathrm{h}_{2}}$ & $(8)$ \\
\hline DRX grain size & $\mathrm{d}_{\mathrm{DRX}}(\gamma, \beta)=\mathrm{b}_{1}(\gamma, \beta) \times \mathrm{Z}^{\mathrm{b}_{2}(\gamma, \beta)}$ \\
\hline DRX kinetics & $\mathrm{X}_{\mathrm{DRX}(\gamma, \beta)=1-\exp \left(\mathrm{k}(\gamma, \beta)\left(\frac{\varepsilon-\varepsilon_{\mathrm{cr}}}{\varepsilon_{\mathrm{ss}}-\varepsilon_{\mathrm{cr}}}\right)\right.}^{\mathrm{q}(\gamma, \beta)}$ \\
\hline Flow stress & $\sigma_{\mathrm{y}}=\left\{\left(1-\left(\mathrm{X}_{\gamma}+\mathrm{X}_{\beta}\right)\right) \sigma_{0}+\left(\mathrm{X}_{\gamma}+\mathrm{X}_{\beta}\right) \sigma_{1} \quad\right.$ if $\varepsilon>\varepsilon_{\mathrm{cr}}$ & $(10)$ \\
\hline
\end{tabular}

The main feature of this model is the ability to show a right concave down course of the strain hardening rate in the so-called Kocks-Mecking plot (Figure 1b), as observed experimentally. Other models, which were derived in terms of dislocation theory, are not applicable to the TNB-V4 alloy since they cannot reproduce this right curvature in the Kocks-Mecking plots. An overview of various dislocation-based models was presented in a previous work of the authors [21]. The model was implemented into the commercial FE system Q-Form using the Lua programming interface.
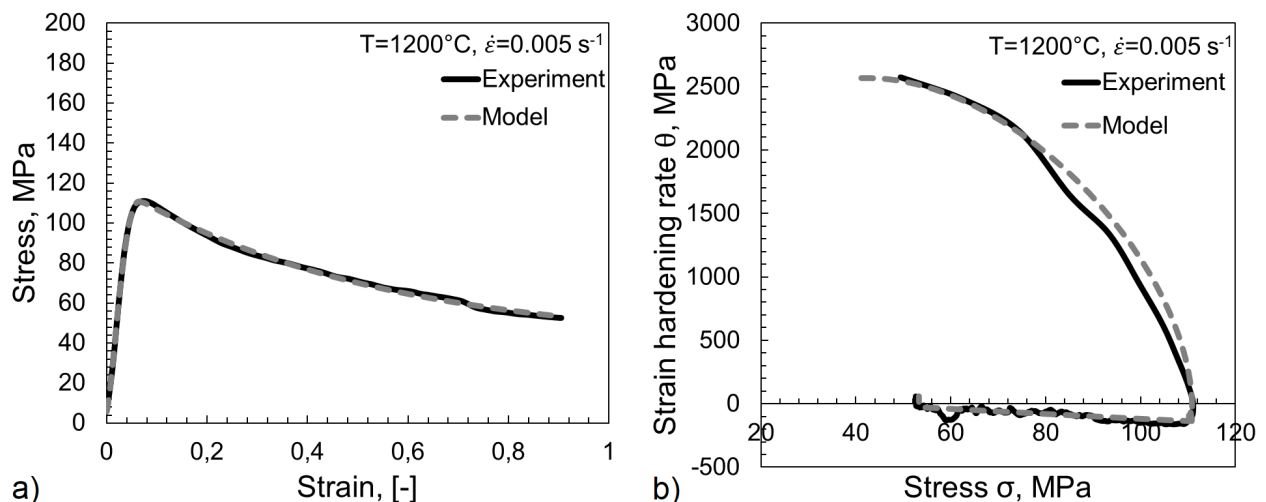

Figure 1. Model prediction vs. experimental data; (a) flow curve of TNB-V4; (b) Kocks-Mecking plot of TNB-V4 [21].

To use the material model in the design of the batch forging process, it first needed to be validated. Examination of the microstructure for comparison with the model was conducted with a deformation dilatometer. The parameters were determined from the FE simulation study of a compressor blade forging process. The tests were performed with various strain rates in agreement with data history obtained from the simulations. The software used in this study was the FE program Q-Form. Figure 4 shows 3D FE model for compressor blade forging. The process was carried out in a single stroke from a preformed billet. The upper and lower dies were modelled as rigid bodies. The temperature of the billet was varied between $1150{ }^{\circ} \mathrm{C}$ and $1300{ }^{\circ} \mathrm{C}$ in increments of $50{ }^{\circ} \mathrm{C}$. The forging speeds used was $0.01,0.1$ and $1 \mathrm{~mm} / \mathrm{s}$. The preform billet was meshed with 23,307 tetrahedral elements (5256 surface and 18,051 volume elements), and the final part had 302,573 tetrahedral elements (51,294 surface and 251,279 volume elements). The friction between dies and billets along the contact surface was assumed 
to follow a Coulomb friction factor of 0.35 . The simulation includes the preheating of the billet and closing the cavity with the upper die.

\subsection{Material and Workpiece}

The TiAl alloy known as TNB-V4 with the composition given in Table 2 was used in this work. The alloy was processed by VAR melting and hot isostatic pressing at $1260{ }^{\circ} \mathrm{C}$ for $4 \mathrm{~h}$ with a pressure of 200 bar.

Table 2. Nominal composition of TNB-V4 TiAl (at $\%$ ).

\begin{tabular}{cccc}
\hline Al & Nb & Mo & B \\
\hline 44.5 & 6.25 & 0.8 & 0.1 \\
\hline
\end{tabular}

The maximum operating temperatures of coated TiAl alloys allows usage in two areas of the jet engine, the compressor and the low-pressure turbine. Compressor blades are smaller and consist of blade and blade root. Turbine blades typically consist of blade, blade root and shrouding band. To limit the tooling costs, the smaller compressor blade was selected as the workpiece for the design of the batch forging process.

\subsection{Batch Process Design}

Isothermal forging requires slow deformation with cross head speeds in the order of $0.1 \mathrm{~mm} / \mathrm{s}$. In order to achieve this, a $17 \mathrm{MN}$ hydraulic press (Oilgear/Presstec, Figure 2) was adapted by installing a second hydraulic unit for isothermal forging in parallel to the standard unit, which allows for controlled motion of the ram with velocities as low as $0.05 \mathrm{~mm} / \mathrm{s}$.

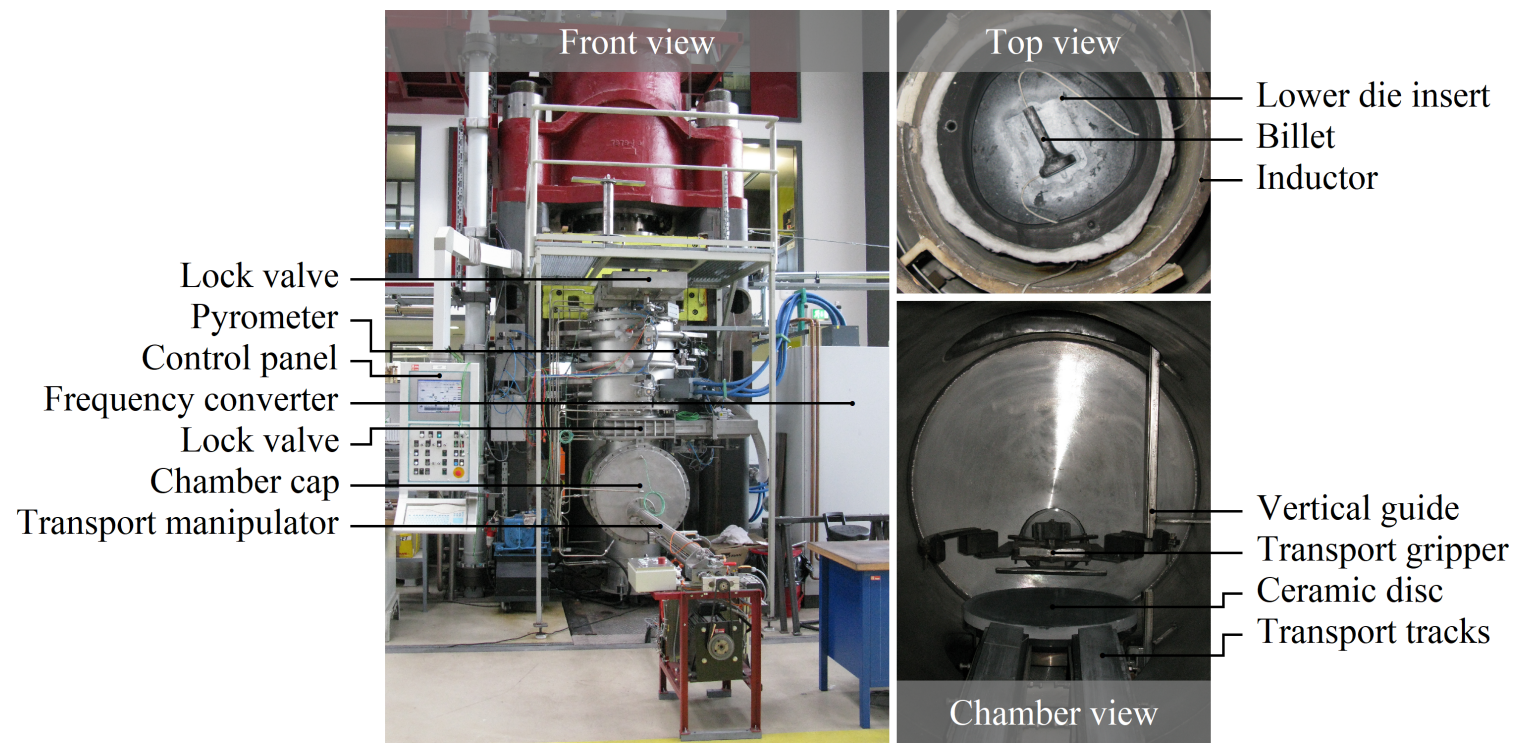

Figure 2. Forging center at $\mathrm{KuF}$ showing the batch processing system.

In order to protect the forging dies and billets, isothermal forging of TiAl has to be carried out in a protective atmosphere or vacuum. To achieve this, the forging center was equipped with a sealable double-walled, water-cooled cylindrical chamber, which encompasses the upper and lower ram. The water-cooling makes it possible to keep the process heat away from the press ram, guides and the frame. Based on this unit, the forging center can be configured to allow for batch processing using preassembled die sets and forging with stationary dies. Figure 3 illustrates the lock and transport system developed for batch processing which is connected to the cylindrical forging chamber. The preassembled die set containing the billet was inserted cold and heated to forging temperature in 
the input/output section (a). This part of the lock system is connected to the press chamber (b) using a hydraulic jack (c) to move the die set vertically, and a spindle-driven linear axis (d) to feed the die set horizontally in and out of the press chamber. Using this setup, the forging press chamber was able to operate in vacuum or a protective atmosphere.
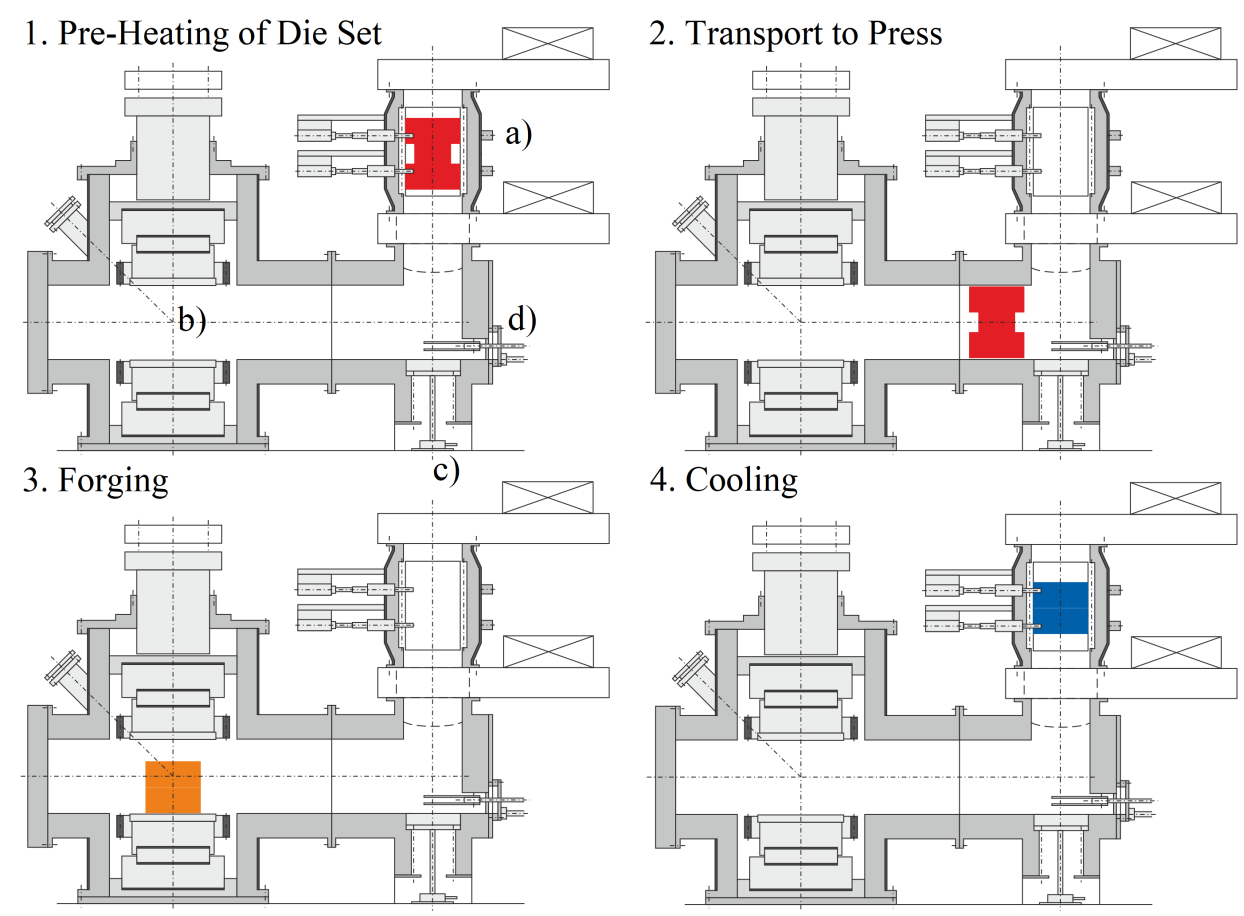

Figure 3. Press and transport design: (a) input/output section; (b) press chamber; (c) vertical transport; (d) horizontal transport.

\subsection{Die Set Design}

The die set for batch processing (Figure 4) consisted of 6 components including the insulation mat. The upper and lower dies were designed as inserts, which were fastened to die bases. A sleeve encompasses the die set and serves as both a thermal insulator and a mechanical guide for the inserts. Both the sleeve and the die bases consist of commercial graphite TTK-50. The die inserts consist of carbon fiber reinforced silicon carbide $(\mathrm{C} / \mathrm{SiC})$ [22]. The die set was insulated with a Fiberfrax $\mathrm{Z}$ mat. The die set schematic and the die set with insulation mat is displayed in Figure 4. As indicated by the blue square, only the upper and lower die inserts and the billet was modeled in simulations.
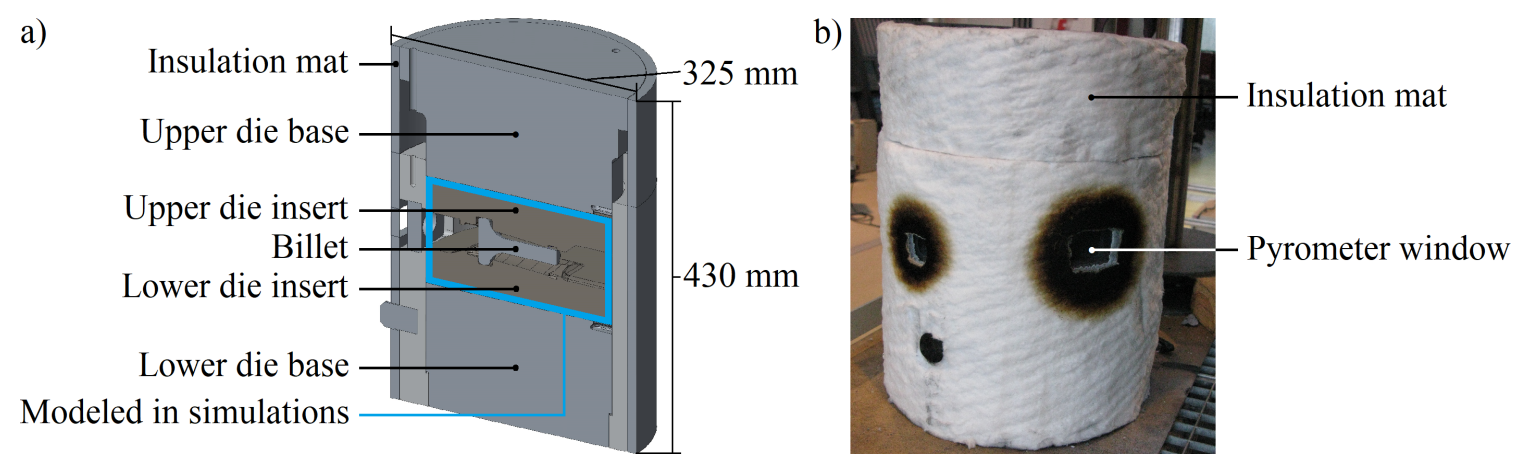

Figure 4. (a) CAD of the die set; (b) physical die set with insulation mat. 


\subsection{Forging Trials}

Forging experiments were carried out using the batch processing transport system and die set. The compressor blades were forged in one step using a $17 \mathrm{MN}$ hydraulic press with a total stroke length of $29 \mathrm{~mm}$. The billets were lubricated with a boron nitride layer onto which a water-based graphite lubricant was applied. The compressor blade was forged with a preheating temperature of $1340{ }^{\circ} \mathrm{C}$ determined from the heating trials (Section 4.4), and a ram speed of $0.1 \mathrm{~mm} / \mathrm{s}$ determined from the finite element analysis (Section 4.2), as the experiments and simulation study revealed these conditions as suitable.

\subsection{Heating Trials}

The process window of the TNB-V4 alloy is from $1250{ }^{\circ} \mathrm{C}$ to $1280{ }^{\circ} \mathrm{C}$. To determine a sufficient preheating temperature which allows the die set to remain inside this window during forging, heat loss experiments were conducted. The evolution of the temperature drop of the die set was measured with a pyrometer, and compared to the transport times of the batch processing setup (Section 4.3). Two separate experiments were conducted; one where the die set was kept stationary and one where it was run through the transport system to the press. The temperature evolution was similar in both cases, therefore only the stationary results are displayed.

\section{Results and Discussion}

\subsection{Model Validation}

Figure 5 displays the strain history, which was extracted from the FE analysis and implemented into the dilatometer test. A cylindrical specimen was tested at $1260{ }^{\circ} \mathrm{C}$, quenched after forming and analyzed for microstructure evolution. This procedure was preferred for validation because the forged blade could not be extracted from the die set and quenched sufficiently fast to conserve the microstructure obtained after isothermal forming.

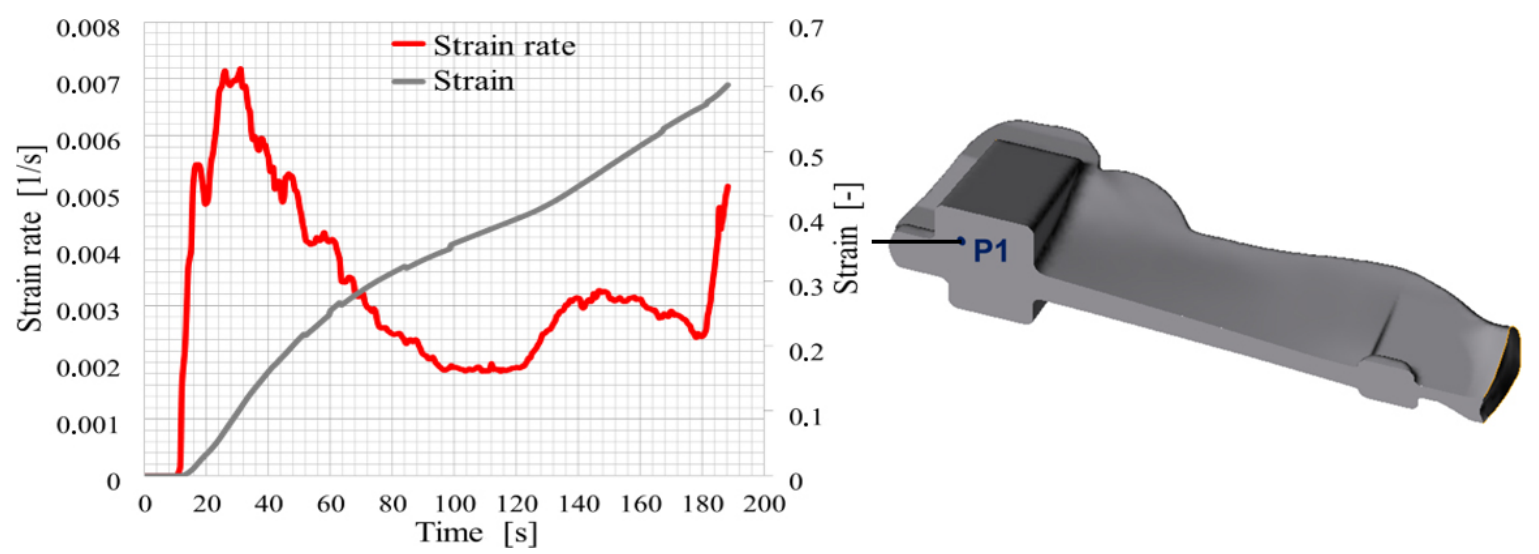

Figure 5. Conditions for compression testing extracted from the FEA and implemented in dilatometer tests to validate the model.

Figure 6 illustrates the comparison between the predicted grain sizes from the simulation and the measured grain sizes from the compression experiments. The microstructure of TNB-V4 consists of the fine recrystallized fractions of $\beta / \beta_{0}$-phase (white), the $\gamma$-phase (dark gray), and the $\alpha$-phase (light gray). The grain sizes were measured in the same point (P1 in Figure 6) in both the final forged part and the FE model. Table 3 displays the calculated and measured grain sizes. As is evident, the model predictions show good agreement with the experimental results. 


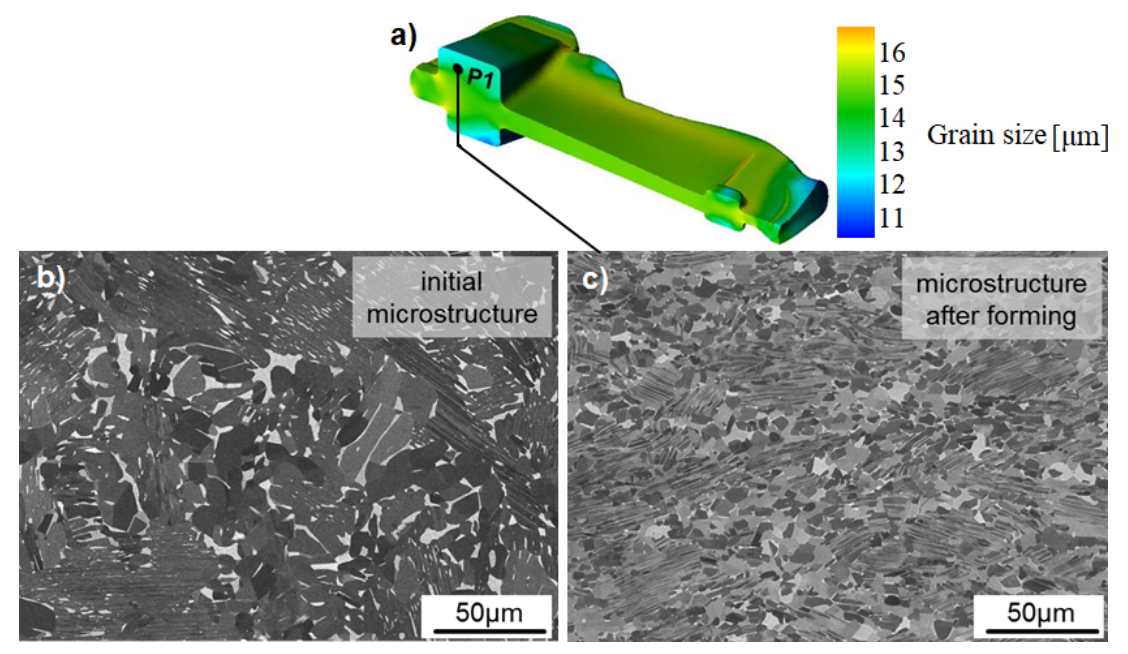

Figure 6. (a) predicted grain sizes by simulation; (b) initial experimental microstructure; (c) final experimental microstructure.

Table 3. Calculated and measured grain sizes.

\begin{tabular}{ccc}
\hline Point P1 & Calculated Grain Size $[\mu \mathrm{m}]$ & Measured Grain Size $[\mu \mathrm{m}]$ \\
\hline$\gamma$-phase & 12.71 & 10.37 \\
\hline$\beta / \beta_{0}$-phase & 12.86 & 10.24 \\
\hline
\end{tabular}

\subsection{Simulated Die Stresses}

By systematic variation of the forging temperature and ram speed, a contour map of the maximum tool stress values for the top die was created, as shown in Figure 7a. The top die was the most critical, as it underwent the highest stresses in all cases. The locations of the maximum top die stresses are displayed in Figure $7 b$, they alternated slightly between two nodes as shown. In total 12 simulations were run. The maximum tool stresses found ranged from around $120 \mathrm{MPa}$ to around $870 \mathrm{MPa}$, depending on forging velocity and temperature. The process window of the TNB-V4 alloy is from $1250{ }^{\circ} \mathrm{C}$ to $1280^{\circ} \mathrm{C}$, as indicated in Figure $7 \mathrm{a}$. The maximum bearable stress of the die material $(\mathrm{C} / \mathrm{SiC})$ has been reported to be around $350 \mathrm{MPa}$ [23], which is roughly indicated by the red line in the contour plot. Thus, the simulation results predicted that the combinations of forging velocity and temperatures in the area under the red line were acceptable for the die material.
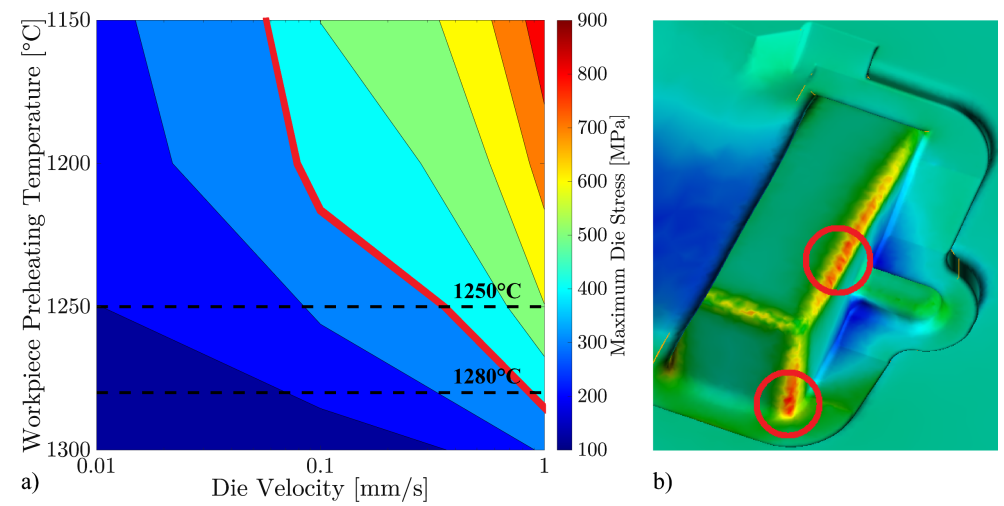

b)

Figure 7. (a) Contour plot of simulated max tool stresses; (b) max stress locations in the top die. 


\subsection{Forging}

Figure 8 illustrates the forging process chain. The workpiece and die set were assembled and heated together by induction to $1340{ }^{\circ} \mathrm{C}$ (b) before being transported to the forging press (c). The transport time from preheating to the press was around $45 \mathrm{~s}$, including around $10 \mathrm{~s}$ for the press make contact with the tool set. The forging time was around $290 \mathrm{~s}$ (d), i.e., nearly $5 \mathrm{~min}$. Transport time back was around $35 \mathrm{~s}$.

b)

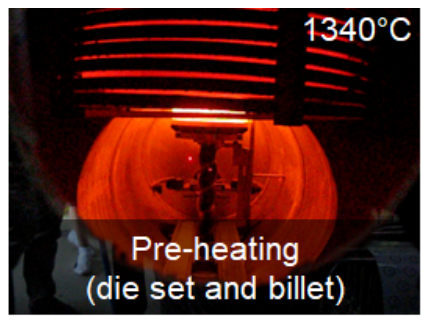

a)

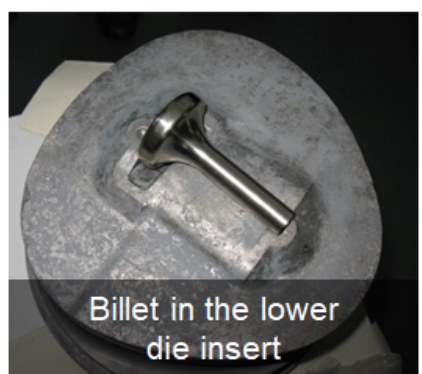

c)

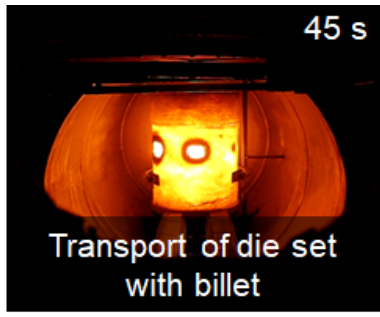

Die material: Carbon fiber reinforced silicon carbide $(\mathrm{C} / \mathrm{SiC})$.

Lubricate: Boron nitride and water-based graphite.

Forging velocity: $0.1 \mathrm{~mm} / \mathrm{s}$

Forging stroke: $29 \mathrm{~mm}$

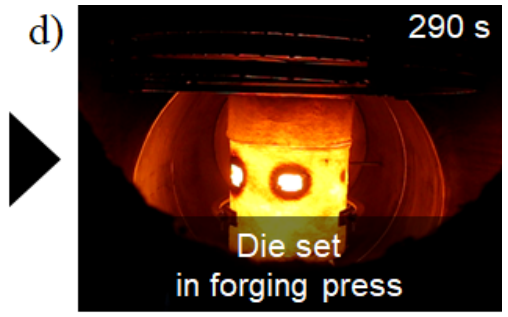

e)

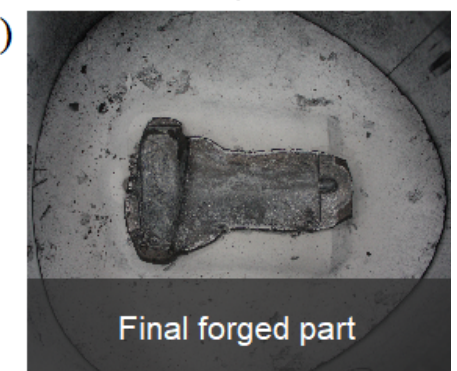

Figure 8. Illustration of the process chain; (a) Billet in the lower die insert; (b) preheating; (c) transport to press; (d) die set in press; (e) final forged part.

The maximum experimental forging force reached at the end of the stroke was around $360 \mathrm{kN}$, which corresponded well with the simulated max force. Thus, the $17 \mathrm{MN}$ press used in this investigation is theoretically able to forge a large number of parts per batch. However, this number is limited by technical as well as economic constraints, as a bigger die set requires a bigger and more robust transport system with a more powerful inductor, increasing operating and energy costs.

\subsection{Heat Loss}

Experiments were run to assess the temperature evolution of the billet with varying preheating temperatures, as displayed in Figure 9. In total 4 tests were run before the optimal preheating temperature was found (blue line). From the end of preheating to the start of forging (around $45 \mathrm{~s}$, Section 4.3), the workpiece had cooled down around $5{ }^{\circ} \mathrm{C}$, and continued to cool down during forging. As indicated in the diagram, a preheating temperature of $1340^{\circ} \mathrm{C}$ produced a forging temperature of around $1250^{\circ} \mathrm{C}$ at the end of the process. This is at the lower boundary of the process window for the TNB-V4 alloy, however the material was overheated until around the 4 min mark as shown in Figure 9. Overheating was considered the best alternative given the available equipment, as forging below the process window can result in high stresses and risk of damaging the dies.

Jaffee et al. [24] mentions that the negative effects of overheating $\alpha+\beta$ titanium alloys are not as detrimental as compared to other materials (i.e., steel alloys). However, specific studies covering the impact of overheating on the microstructure evolution of TiAl alloys during forging are missing from the literature. Thus, this issue needs to be covered in future research. Determining the process windows of other TiAl alloys to assess their viability for batch processing is also an interesting topic for future work. Measures to reduce heat loss (e.g., a better or thicker insulation mat) may result in a 
slower temperature drop, allowing more of the forging process to occur inside the process window at even lower preheating temperatures.

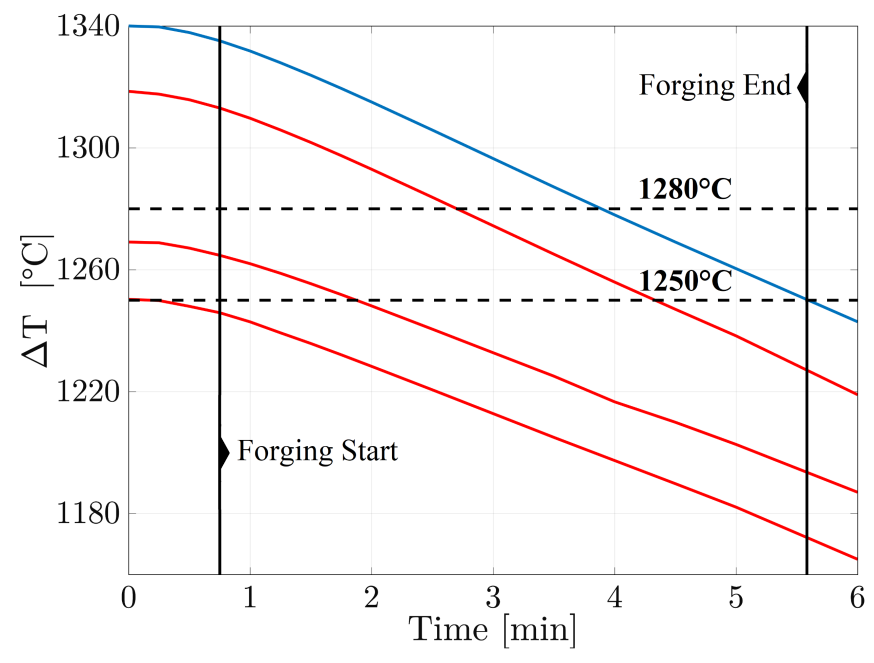

Figure 9. Temperature drop of the billet.

\subsection{Scaling Up of the Process}

Due to cost restrictions, the authors were only able to produce a die set able to forge 1 compressor blade at a time. Future research can aim at scaling up the process developed and presented in this work to accommodate a bigger die set, and attempt to forge 2 or 4 parts per batch. One of the main challenges is producing a die which distributes the stresses symmetrically and uniformly, as a die set with more than one engraving will inherently have asymmetries and stresses removed from the die center. Especially when forging slanted parts such as compressor blades, the torque and rotational forces which may arise are important to consider. These can be counteracted with stiffer support structures and stronger fastenings (e.g., bigger bolts). However, these will in turn cause more heat loss from the die set and increase costs.

The material model presented in this work can be used in the design of dies with 2 or more engravings. A proposed die FE model for batch processing of 2 compressor blades is displayed in Figure 10. The simulation parameters and the billet as described in Section 3.1 for 1 compressor blade were used. The results indeed showed residual torque stresses in the upper die, produced by the geometry of the 2 engravings, indicating that this is an important topic for future work in the field of batch processing.
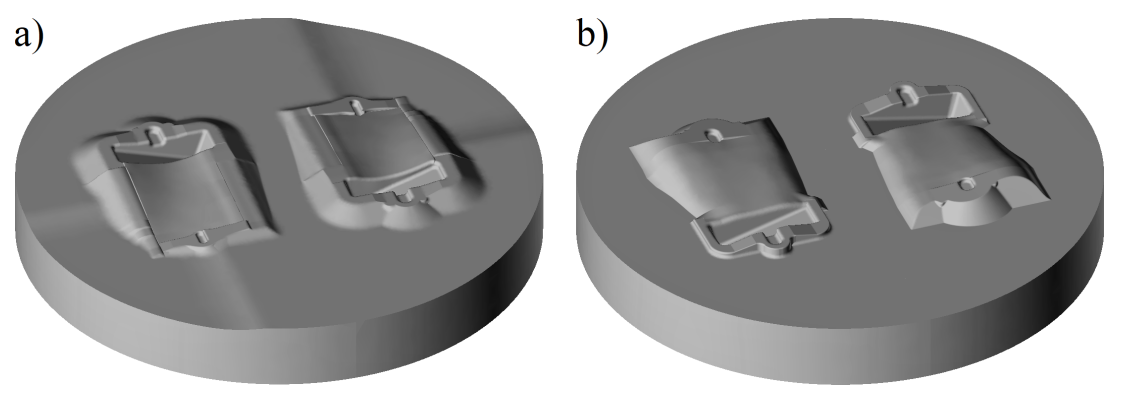

Figure 10. Dies for batch processing of 2 compressor blades; (a) bottom die; (b) top die.

\section{Cost Analysis}

Economic considerations are of crucial importance for industrial production of TiAl forgings. In this section, a qualitative comparison of unit costs between isothermal forging of 1 and 2 parts 
with a stationary die, and isothermal forging of 2 and 4 parts using batch processing is presented. The equations and parameters used for the cost analysis model are given, as well as the produced results. For a lot size $\mathrm{L}$, the unit costs $\mathrm{C}$ are

$$
\mathrm{C}=\frac{\mathrm{C}_{\text {die }}+\mathrm{C}_{\text {setup }}}{\mathrm{L}}+\mathrm{C}_{\text {process }}+\mathrm{C}_{\text {billet }}
$$

The costs for the dies (number $\mathrm{n}_{\text {die }}$ ) are

$$
\mathrm{C}_{\text {die }}=\mathrm{n}_{\text {die }}\left(\rho_{\text {die }} \mathrm{V}_{\text {die }} \mathrm{C}_{\text {Mo }}+\mathrm{C}_{\text {mill }}\right)
$$

For production with stationary dies, at least two dies are needed to avoid idle time during die maintenance. For batch processing, at least three die sets are needed which are circulated continuously, and a fourth die set would avoid idle time of the press during maintenance of a die set. It is assumed that the die engraving has to be re-machined after 1000 forgings. The process costs are

$$
\begin{gathered}
C_{\text {process }}=\left(t_{f}+t_{h}\right)\left(C_{L}+C_{E}\right) \\
C_{\text {setup }}=t_{s}\left(C_{L}+C_{E}\right)
\end{gathered}
$$

Finally, the material costs per billet are

$$
\mathrm{C}_{\text {billet }}=\rho_{\mathrm{TiAl}} \mathrm{V}_{\mathrm{billet}} \mathrm{C}_{\mathrm{TiAl}}
$$

The variables assumed for the cost model are given in Tables 4 and 5, and are based on the experiences gained during the design of the press system and the forging experiments. They only allow for a qualitative comparison of the two process routes. The main difference between the routes are larger die investments for batch processing, and the long handling and setup times for die change (approximately one working day) with the stationary die. The die volumes are scaled up when more than one engraving is present.

Table 4. Cost comparison input data.

\begin{tabular}{cccc}
\hline Cost Type & Symbol & Unit & Value \\
\hline Cost of die material & $\mathrm{C}_{\mathrm{Mo}}$ & $\mathrm{USD} / \mathrm{kg}$ & 140 \\
Cost of TiAl & $\mathrm{C}_{\mathrm{TiAl}}$ & $\mathrm{USD} / \mathrm{kg}$ & 200 \\
Density Mo & $\mathrm{PMo}_{\mathrm{Mo}}$ & $\mathrm{kg} / \mathrm{m}^{3}$ & 10,200 \\
Density TiAl & $\rho_{\mathrm{TiAl}}$ & $\mathrm{kg} / \mathrm{m}^{3}$ & 4200 \\
Labour cost per hour & $\mathrm{C}_{\mathrm{L}}$ & $\mathrm{USD} / \mathrm{h}$ & 175 \\
Equipment hourly rate & $\mathrm{C}_{\mathrm{E}}$ & $\mathrm{USD} / \mathrm{h}$ & 590 \\
Forging ram speed & $\mathrm{V}$ & $\mathrm{mm} / \mathrm{s}$ & 0.1 \\
Handling time single part & $\mathrm{T}_{\mathrm{h}, \mathrm{p}}$ & $\mathrm{s}$ & 10 \\
Handling time die set & $\mathrm{T}_{\mathrm{h}, \mathrm{die}}$ & $\mathrm{s}$ & 35 \\
\hline
\end{tabular}

Table 5. Size dependent part parameters.

\begin{tabular}{ccccc}
\hline Parameter & Symbol & Unit & Small Part & Large Part \\
\hline Billet volume & $\mathrm{V}_{\mathrm{b}}$ & $\mathrm{mm}^{3}$ & 60,000 & 100,000 \\
Die volume & $\mathrm{V}_{\text {die }}$ & $\mathrm{mm}^{3}$ & $4,200,000$ & $11,000,000$ \\
Chip volume & $\mathrm{V}_{\mathrm{en}}$ & $\mathrm{mm}^{3}$ & $1,000,000$ & 900,000 \\
Set-up time & $\mathrm{t}_{\mathrm{s}}$ & $\mathrm{s}$ & 28,800 & 60 \\
Forging time & $\mathrm{t}_{\mathrm{f}}$ & $\mathrm{s}$ & 310 & 380 \\
\hline
\end{tabular}


Figure 11 shows the ratio of unit costs for the stationary die process $\left(\mathrm{C}_{\mathrm{SD}}\right)$ and batch processing $\left(C_{B P}\right)$ for small (a) and large (b) parts respectively. This diagram was created using the equations and parameters presented. For the stationary die, 1 and 2 engravings were used, as more engravings would increase the idle time of the press during part handling and increase the thermal load on the gripper. For batch processing, 2 and 4 engravings were used. The solid line represents the ratio of $C_{S D} / C_{B P}$ for 1 part forged with the stationary die and 2 parts forged using batch processing, the dotted line represents 2 parts forged with the stationary die and 2 parts forged using batch processing, finally the dashed line represents 2 parts forged with the stationary die and 4 parts forged using batch processing. As indicated, forging with the stationary die provides a cost advantage when the value of $C_{S D} / C_{B P}$ is below 1 , while batch processing is favorable when the value exceeds 1 . The comparison shows that for small parts and large lot sizes, batch processing of 2 and 4 parts always offer a cost advantage. If the number of engravings is equal, this advantage diminishes with increasing lot size. For large parts, the stationary die is more favorable for smaller lot sizes. Thus, batch processing requires a large lot size, which is a consequence of the fact that batch processing requires at least 3 die sets to avoid idle times. If the lot size is small so that no die change is necessary (low tool wear), stationary die forging with two engravings is still the most economical.
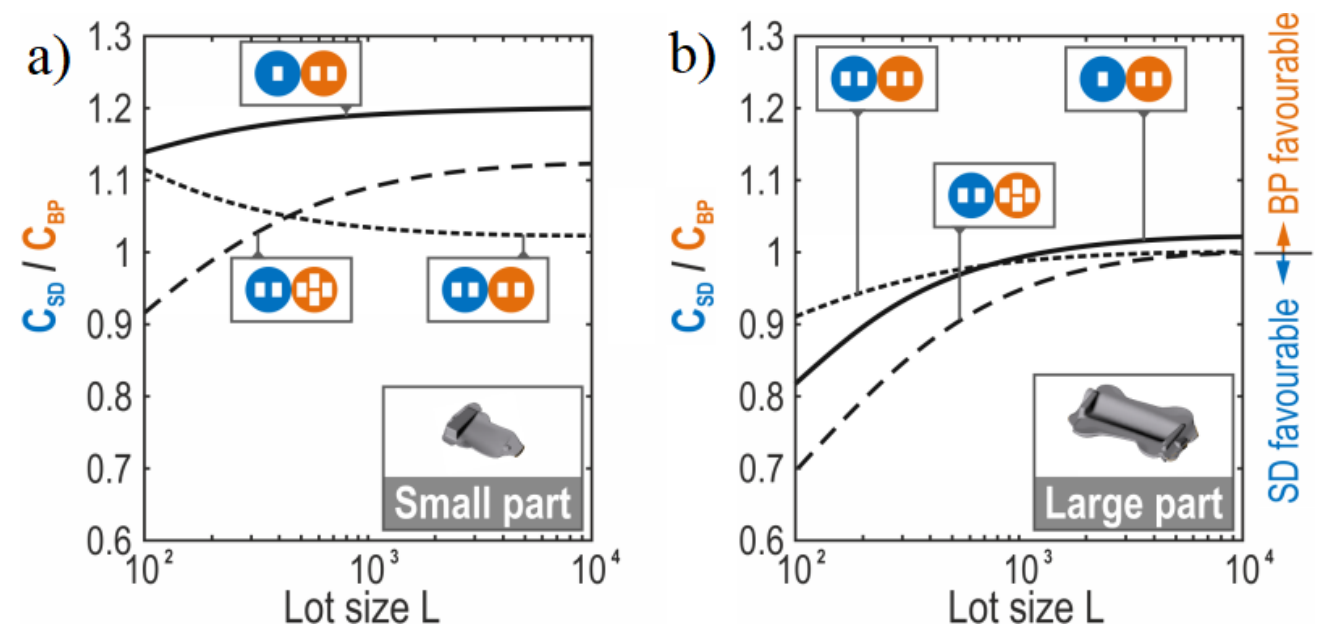

Figure 11. Cost ratio of stationary die (SD) and batch processing (BP) for; (a) small parts; (b) large parts.

\section{Conclusions}

This work has provided the foundations for batch processing of TNB-V4 TiAl (Ti-44.5Al$6.25 \mathrm{Nb}-0.8 \mathrm{Mo}-0.1 \mathrm{~B})$. A new process design for transport and handling of preassembled and preheated die sets has been developed and presented. Material modelling and experiments were performed to determine and validate the forging parameters, and a cost analysis compares batch processing to stationary die forging. The main conclusions drawn from this investigation are:

- A material model was successfully implemented into the FE program Q-Form, validated and applied to identify the TNB-V4 process window, forging speed and die stresses. The grain sizes predicted by the model showed good agreement with the experimental ones.

- Due to transport time and insufficient insulation, overheating the die set above the process window was necessary. Future research should aim at investigating the potentially negative effects of overheating TiAl alloys, and determining the amount of time overheating can be applied.

- Batch processing seems to offer cost advantages for smaller parts and large lot sizes, while stationary dies are favorable for larger parts and smaller production lots. 
Acknowledgments: The authors would like to thank the Ministry for Economy of the Federal State Brandenburg within the joint research project "PräziTal" (grant no. 80133830). Furthermore, the financial support of the project partners Leistritz Turbinentechnik GmbH (Remscheid, Germany) and Rolls-Royce Deutschland Ltd. \& Co. KG (Dahlewitz, Germany) is gratefully acknowledged. The material modeling was accomplished as part of the project BA 4253/4-1 funded by the German Research Foundation (DFG). The authors are grateful for the financial support. The authors are grateful to the colleagues from the Chair of Physical Metallurgy and Materials Technology of BTU Cottbus-Senftenberg for the preparation of the metallographic images used in this study.

Author Contributions: Markus Bambach and Martin Günther conceived and designed the experiments; Martin Günther performed the experiments; Alexander Sviridov implemented the model; Alexander Sviridov and Johan Andreas Stendal performed the simulations; Markus Bambach, Alexander Sviridov and Irina Sizova analyzed the data; Markus Bambach, Irina Sizova and Johan Andreas Stendal wrote the paper.

Conflicts of Interest: The authors declare no conflict of interest.

\author{
Abbreviations \\ The following abbreviations are used in this manuscript: \\ TNB TiAl with $\mathrm{Nb}$ and $\mathrm{B}$ as the main alloying elements \\ TNM TiAl with $\mathrm{Nb}$ and Mo as the main alloying elements \\ DRX Dynamic Recrystallization \\ DRV Dynamic Recovery \\ VAR Vacuum Arc Remelting \\ FE Finite Element \\ $\mathrm{KuF}$ Chair of Mechanical Design and Manufacturing
}

\title{
References
}

1. Clemens, H.; Kestler, H. Processing and applications of intermetallic $\gamma$-TiAl based alloys. Adv. Eng. Mater. 2000, 2, 551-570.

2. Clemens, H.; Smarsly, W. Light-weight Intermetallic Titanium Aluminides-Status of Research and Development. Adv. Mater. Res. 2011, 78, 551-556.

3. Aguilar, J.; Schievenbusch, A.; Kättlitz, O. Investment casting technology for production of TiAl low pressure turbine blades-Process engineering and parameter analysis. Intermetallics 2011, 19, 757-761.

4. Hautmann, D. Titanium Aluminide-A Class All by Itself; Aero Report; MTU Aero Engines AG: Munich, Germany, 2013.

5. Olofson, C.T.; Boulger, F.W.; Gurklis, J.A. Machining and Grinding of Titanium and Its Alloys; NASA Technical Memorandum; NASA George C. Marshall Space Flight Center: Huntsville, AL, USA, 1965.

6. Beranoagirre, A.; López de Lcalle, L.N. Grinding of Gmma TiAl Intermetallic Alloys. Procedia Eng. 2013, 63, 489-498.

7. Wu, F.; Xu, W.; Jin, X.; Zhong, X.; Wan, X.; Shan, D.; Guo, B. Study on Hot Deformation Behavior and Microstructure Evolution of Ti-55 High-Temperature Titanium Alloy. Metals 2017, 7, 319, doi:10.3390/met7080319.

8. Millett, J.C.F.; Brooks, J.W.; Jones, I.P. Assessment and modelling of isothermal forging of intermetallic compounds Part 1-TiAl. Mat. Sci. Technol. 1999, 15, 697-704.

9. Blackwell, P.L.; Brooks, J.W.; Bate, P.S. Development of microstructure in isothermally forged Nimonic alloy AP1. Mat. Sci. Technol. 1998, 14, 1181-1188.

10. Semiatin, S.L.; Seetharaman, V.; Ghosh, A.K. Plastic flow, microstructure evolution, and defect formation during primary hot working of titanium and titanium aluminide alloys with lamellar colony microstructures. Philos. Trans. R. Soc. Lond. A 1999, 357, 1487-1512.

11. Tetsui, T.; Shindo, K.; Kaji, S.; Kobayashi, S.; Takeyama, M. Fabrication of TiAl components by means of hot forging and machining. Intermetallics 2005, 13, 971-978.

12. Brooks, J.W.; Dean, T.A.; Hu, Z.M.; Wey, E. Three-dimensional finite element modelling of a titanium aluminide aerofoil forging. J. Mater. Process. Technol. 1998, 80-81, 149-155.

13. Semiatin, S.L.; Frey, N.; El-Soudani, S.M.; Bryant, J.D. Flow Softening and Microstructure Evolution during Hot Working of Wrought Near-Gamma Titanium Aluminides. Metall. Trans. A 1992, 23, 1719-1735. 
14. Schmoelzer, T.; Liss, K.D.; Kirchlechner, C.; Mayer, S.; Stark, A.; Peel, M.; Clemens, H. An in-situ high-energy $\mathrm{X}$-ray diffraction study on the hot-deformation behavior of a beta-phase containing TiAl alloy. Intermetallics 2013, 39, 25-33.

15. Cheng, L.; Xue, X.; Tang, B.; Kou, H.; Li, J. Flow characteristics and constitutive modeling for elevated temperature deformation of a high $\mathrm{Nb}$ containing TiAl alloy. Intermetallics 2014, 49, 23-28.

16. Laasraoui, A.; Jonas, J.J. Prediction of steel flow stresses at high temperatures and strain rates. Metall. Mat. Trans. A 1991, 22, 1545-1558.

17. Werner, R.; Lindemann, J.; Clemens, H.; Mayer, S. Constitutive Analysis of the Flow Curve Behavior of an Intermetallic $\beta$-solidifying $\gamma$-TiAl-based Alloy and Microstructural Characterization of the Deformed State. BHM 2014, 159, 286-288.

18. Godor, F.; Werner, R.; Lindemann, J.; Clemens, H.; Mayer, S. Characterization of the high temperature deformation behavior of two intermetallic TiAl-Mo alloys. Mater. Sci. Eng. A 2015, 648, 208-216.

19. Schwaighofer, E.; Clemens, H.; Lindemann, J.; Stark, A.; Mayer, S. Hot-working behavior of an advanced intermetallic multi-phase $\gamma$-TiAl based alloy. Mater. Sci. Eng. A 2014, 614, 297-310.

20. Cingara, A.; McQueen, H.J. New formula for calculating flow curves from high temperature constitutive data for 300 austenitic steels. J. Mater. Process. Technol. 1992, 36, 31-42.

21. Bambach, M.; Sizova, I.; Bolz, S.; Weiß, S. Devising Strain Hardening Models Using Kocks-Mecking Plots-A Comparison of Model Development for Titanium Aluminides and Case Hardening Steel. Metals 2016, 6, 204, doi:10.3390/met6090204.

22. Hufenbach, W.; Behnisch, T.; Richter, H.; Langkamp, A.; Janschek, P.; Bauer-Partenheimer, K.; Turley, F. Development of Hybrid CMC Forming Dies for High Temperature Precision Forging of Titanium Aluminide. In Proceedings of 7th International Conference on High Temperature Ceramic Matrix Composites (HT-CMC 7), 20-22 September 2010; pp. 531-536.

23. Krenkel, W. Carbon Fibre Reinforced Silicon Carbide Composites (C/SiC, C/C-SiC). In Handbook of Ceramic Composites; Springer: New York, NY, USA, 2005; pp. 117-148.

24. Jaffee, R.I.; Promisel, N.E. The Science, Technology and Application of Titanium; Pergamon Press Ltd.: Oxford, UK, 2013; pp. 79-84.

(C) 2018 by the authors. Licensee MDPI, Basel, Switzerland. This article is an open access article distributed under the terms and conditions of the Creative Commons Attribution (CC BY) license (http://creativecommons.org/licenses/by/4.0/). 